\title{
CDK4/6 inhibitor palbociclib suppresses lgE-mediated mast cell activation
}

\author{
Yi-Bo Hou ${ }^{\dagger}$, Kunmei $\mathrm{Ji}^{\dagger}$, Yue-Tong Sun, Li-Na Zhang and Jia-Jie Chen ${ }^{*}$ (i)
}

\begin{abstract}
Background: Mast cell activation causes degranulation and release of cytokines, thereby promoting inflammation. The aim of this study was to investigate the inhibitory effect of CDK4/6 inhibition on mast cell activation in vitro and in vivo.

Methods: RBL-2H3 rat basophilic leukemia cells (BLCs) and mouse bone marrow-derived mast cells (BMMCs) were sensitized with anti-dinitrophenol (DNP) immunoglobulin (Ig)E antibodies, stimulated with DNP-human serum albumin (HSA) antigens, and treated with the CDK4/6 inhibitor palbociclib. Histological stains were applied to reveal cytomorphological changes. Murine lgE-mediated passive cutaneous anaphylaxis (PCA) and ovalbumin (OVA)-induced active systemic anaphylaxis (ASA) models were used to examine palbociclib effects on allergic reactions in vivo. Western blots were performed to detect the expression of cell signaling molecules associated with mast cell activation.
\end{abstract}

Results: Activated BLCs and BMMCs released copious granule-related mediators (histamine and $\beta$-hexosaminidase), which was reduced by palbociclib in a concentration-dependent manner. Palbociclib inhibited expression of the mast cell activation marker CD63 in activated BLCs and inhibited granule release (visualized with toluidine blue staining) while preventing morphological changes, (elongated shape maintained) and filamentous actin (F-actin) reorganization. Palbociclib suppressed molecular Lyn and/or mitogen-activated protein kinase (MAPK) signaling associated with mast cell activation in stimulated BLCs and attenuated allergic reactions in PCA mice dose dependently. Palbociclib attenuated body temperature reduction and diminished serum histamine levels in ovalbumin OVA-challenged ASA mice.

Conclusion: Palbociclib suppresses IgE-mediated mast cell activation in vitro and in vivo, suggesting that it may be developed into a therapy for mast cell-mediated allergic diseases via inhibition of mast cell degranulation.

Keywords: Mast cells, Palbociclib, CDK inhibitor, Drug repurposing

\section{Introduction}

Common allergic diseases, including asthma, allergic rhinitis, and specific dermatitis, are consequent to hypersensitive immune reactions [1]. In a given year, approximately one in five people in the world are affected by allergic diseases [2]. Socioeconomic development has been associated with an increasing incidence of allergic diseases year over year [3, 4]. Importantly, mast cells, which are major innate immunity effector

\footnotetext{
*Correspondence: chenjj@szu.edu.cn

${ }^{\dagger}$ Yi-Bo Hou and Kunmei Ji contributed equally to this work

Department of Biochemistry and Molecular Biology, School of Medicine,

Shenzhen University, Shenzhen 518060, People's Republic of China
}

cells, play a principal role in inducing allergic inflammation by releasing various mediators, including lipid mediators, chemokines, and cytokines [5]. Thus, mast cells are an attractive target for the treatment of allergic inflammation.

Mast cell activation, which plays a key role in inducing IgE-mediated allergic inflammation, depends on crosslinking of antigen immunoglobulin (Ig)E complexes with the high affinity IgE receptor, commonly referred to as FceRI, on the surface of mast cells $[1,6]$. The subsequent mast cell degranulation that ensues can trigger acute inflammatory reactions and promote chronic allergy progression by secreting histamine, proteases, and chemotactic factors, as well as by engaging in de novo synthesis 
of inflammatory cytokines [5, 7]. During an acute allergic response, histamine, which is a well-established vasodilator, also acts to increase vascular permeability, leading to a low body temperature and leukocyte extraversion from the circulation into local tissues [8]. Therefore, suppression of mast cell activation has the potential to attenuate allergic inflammation [9].

Antihistamine and steroid drugs are common clinical therapies used to treat allergic diseases [10, 11]. Additionally, small molecule inhibitors targeting leukotrienes or histamine receptors have been developed to treat allergic diseases [12]. Mast cell stabilizers that inhibit activated mast cell release (e.g. sodium cromoglycate, nedocromil, and lodisa) have emerged as another potential allergy treatment approach $[13,14]$. Whereas these treatments target allergy symptom control, blockade of mast cell activation represents an opportunity to alleviate the immune dysfunction underlying allergic diseases more directly [15].

Palbociclib (IBRANCE; PD0332991; Pfizer; $\mathrm{C}_{24} \mathrm{H}_{29} \mathrm{~N}_{7} \mathrm{O}_{2}$ ) is an orally available drug approved by the US FDA for the treatment of cancers [16]. Notably, it was approved as a first-line treatment of estrogen receptorpositive $(E R+)$ /human epidermal growth factor receptor 2-negative (HER-) advanced breast cancer based on PALOMA-1 study findings [16, 17]. Palbociclib, is a selective cyclin-dependent kinase (CDK)4/6 inhibitor, with low enzymatic half-maximal inhibitory concentrations for CDK4 (11 nM) and CDK6 (15 nM), that inhibits retinoblastoma protein phosphorylation in early G1 phase, leading to cell cycle arrest and thus suppression of cell proliferation [17].

The effects of CDK4/6 inhibitors, such as palbociclib, on mast cell activation and allergic reactions remain to be clarified.

The aim of this study was to investigate potential antiallergic effects of palbociclib on IgE-mediated mast cell activation. We sensitized mast cells with anti-dinitrophenol (DNP) IgE antibodies and then used DNP-human serum albumin (HSA) antigen stimulation to activate the sensitized mast cells in vitro. We used a murine IgEmediated passive cutaneous anaphylaxis (PCA) model and ovalbumin (OVA)-induced active systemic anaphylaxis (ASA) model to examine the effects of palbociclib on allergic reactions in vivo. Finally, we explored the molecular mechanisms underlying palbociclib effects on IgE-mediated mast cell activation.

\section{Materials and methods Reagents and antibodies}

Palbociclib was purchased from Med Chem Express (Monmouth Junction, NJ). Monoclonal DNP-specific IgE, DNP-HSA, and 4-nitrophenyl
$\mathrm{N}$-acetyl- $\beta$ - $\mathrm{D}$-glucosaminide were obtained from SigmaAldrich (St. Louis, MO). Evans blue, formamide, toluidine blue and mast cell stabilizer ketotifen were obtained from Dalian Meilun Biotechnology Co. Ltd. (Dalian, China). Antibodies targeting the tyrosine-protein kinase Lyn, Tyr397 phosphosphorylated (p)-Lyn, mitogenactivated protein kinase (MAPK) p38, c-Jun N-terminal kinase (JNK) (Abcam, Cambridge, MA), extracellular signal-regulated kinase (ERK)1/2, p-p38 (Thr180/Tyr182), p-JNK (Thr183/Tyr185), glyceraldehyde 3-phosphate dehydrogenase (GAPDH; Santa Cruz Biotechnology, Santa Cruz, CA), and p-ERK1/2 (Thr202/Tyr204) (p-ERK1/2) (Cell Signaling Technology, Beverly, MA) were used. Fluorescein isothiocyanate (FITC)-phalloidin was purchased from Yeasen Biotech Co. Ltd. (Shanghai, China). Lyn inhibitor Bafetinib, ERK inhibitor U0126, JNK inhibitor SP600125 and p38 inhibitor SB203580 were purchased from MedChem Express (Monmouth Junction, NJ, USA). Silencing RNAs (SiRNAs) for knocking down the expression of Lyn were designed and obtained from Gene Pharma (Shanghai, China).

\section{Animals}

Female BALB/c mice (4-5 weeks old) were purchased from Guangdong Medical Laboratory Animal Center (Foshan, China), and housed in a specific pathogenfree environment with a relatively stable temperature $\left(24 \pm 1{ }^{\circ} \mathrm{C}\right)$ and humidity $(55 \pm 10 \%)$ for 1 week before experimentation. The mice were used to isolate bone marrow-derived mast cells (BMMCs) as well as for our PCA and ASA models. All studies involving mice were performed according to protocols approved by the Animal Care and Use Committee of the School of Medicine of Shenzhen University.

\section{Cell culture}

RBL-2H3 rat basophilic leukemia cells (BLCs; Cellcook Biotechnology Co., Guangzhou, China) were cultured in complete Dulbecco's modified eagle medium with $4.0 \mathrm{mM}$ L-glutamine with sodium pyruvate penicillin (100 U/ml), $100 \mu \mathrm{g} / \mathrm{ml}$ streptomycin, non-essential amino acids, and $10 \%$ fetal bovine serum in a humidified incubator at $37^{\circ} \mathrm{C}, 5 \% \mathrm{CO}_{2}$. Mouse bone marrow-derive mast cells (BMMCs) were isolated from BALB/c mouse femurs and cultured in complete RPMI-1640 with $100 \mathrm{U} / \mathrm{ml}$ penicillin, $100 \mu \mathrm{g} / \mathrm{ml}$ streptomycin, $2 \mathrm{mM} \mathrm{L}$-glutamine, $1 \mathrm{mM}$ sodium pyruvate, $10 \mathrm{mM}$ 4-(2-hydroxyethyl)1-piperazineethanesulfonic acid, $10 \%$ fetal bovine serum, and $10 \mathrm{ng} / \mathrm{ml}$ interleukin (IL)-3 and $10 \mathrm{ng} / \mathrm{ml}$ stem cell factor. After 4-6 weeks in culture, mast cell purity reached $\geq 95 \%$, as indicated by flow cytometry detection of cell-surface CD117 and FceRI expression $[18,19]$. 


\section{Measurement of $\beta$-hexosaminidase}

BLCs and BMMCs were dispensed into 24 well-plates, sensitized with $50 \mathrm{ng} / \mathrm{ml}$ anti-DNP IgE for $12 \mathrm{~h}$, and washed with Tyrode's buffer. Palbociclib or other small molecule inhibitors (Lyn inhibitor bafetinib, ERK inhibitor U0126, JNK inhibitor SP600125 and p38 inhibitor SB203580) was then applied for $1 \mathrm{~h}$. Subsequently, after stimulating with $100 \mathrm{ng} / \mathrm{ml}$ DNP-HSA for $30 \mathrm{~min}$, the supernatant and cell lysate were reacted for $1.5 \mathrm{~h}$ with $1 \mathrm{mM}$ 4-nitrophenyl- $N$-acetyl- $\beta$-D-glucosaminide at $37{ }^{\circ} \mathrm{C}$, followed by quenching with $150 \mu \mathrm{l}$ carbonate buffer. Optical density (OD) at $405 \mathrm{~nm}$ was measured with microplate reader (Bio-Rad, USA) [19-21]. We used the following equation to calculate percent $\beta$-hexosaminidase release (\% degranulation):

$$
\frac{(\text { Experimiental release }- \text { Tyrode's release })}{(\text { Triton-X-100 release }- \text { Tyrode's release })} \times 100 \text {. }
$$

\section{Cell viability assay}

BLCs $\left(2 \times 10^{3} /\right.$ well $)$ and BMMCs $\left(1 \times 10^{4} /\right.$ well $)$ were cultured in 96-well plates for $24 \mathrm{~h}$ and then treated with palbociclib for $24 \mathrm{~h}$ (as above). Cell viability was measured with Cell Counting Kit 8 (Med Chem Express, Monmouth Junction, NJ) according to the manufacturer's protocol.

\section{Histamine release measurement}

BLCs were placed in 24 well-plates $\left(2 \times 10^{5}\right.$ cells/well), sensitized with $50 \mathrm{ng} / \mathrm{ml}$ anti-DNP IgE for $12 \mathrm{~h}$, washed twice with Tyrode's buffer, and then treated with experimentally indicated concentrations of palbociclib for $1 \mathrm{~h}$. After stimulating with $100 \mathrm{ng} / \mathrm{ml}$ DNP-HSA for $20 \mathrm{~min}$, histamine levels in culture media were determined with enzyme-linked immunosorbent assay (ELISA) kits (IBL, Germany), according to the manufacturer's protocol [21].

\section{Flow cytometry}

CD63 expression can be used as an index of mast cell degranulation [22]. After stimulation with DNP-HSA, BLCs pretreated with or without palbociclib were washed with phosphate buffered saline (PBS), labeled with PE-CD63 antibody (Millenia Biotec, Auburn, CA), and detected by flow cytometric analysis (Cytoflex flow analyzer, Beckman Coulter, CA).

\section{Toluidine blue staining}

Toluidine blue staining was used to reveal mast cell activation as evidenced by deposition of metachromatic granules against a pale blue background [23, 24]. BLCs were incubated with $250 \mu \mathrm{l}$ of $4 \%$ paraformaldehyde/ PBS for $30 \mathrm{~min}$ at room temperature. The fixed cells were stained with $300 \mu \mathrm{l}$ of toluidine blue dye $(1 \% \mathrm{w} / \mathrm{v}$ in $0.9 \%$ saline solution, $\mathrm{pH}$ 2.5) for $30 \mathrm{~min}$. The stained cells were observed with an inverted microscope (Carl Zeiss, Goettingen, Germany) [23].

\section{Microfilament staining}

Filamentous actin (F-actin) is involved in mast cell degranulation [24, 25]. Because phalloidin binds F-actin specifically, we used FITC-phalloidin staining to observe F-actin changes. BLCs were fixed in $4 \%$ paraformaldehyde in PBS for $30 \mathrm{~min}$, then washed twice with PBS and permeated with $0.1 \%$ T-X100 PBS for 3 min. After washing with PBS, cellular F-actin was stained with $100 \mathrm{nM}$ FITC-phalloidin for $30 \mathrm{~min}$. Cells were imaged with a fluorescence microscope (Carl Zeiss, Goettingen, Germany) via a FITC channel (excitation $/$ emittance $=496 / 516 \mathrm{~nm}$ ) [25].

\section{SiRNA transfection}

Rat Lyn-specific siRNA sequences with the following sequences were designed and synthesized by GenePharma Co. (Shanghai, China): 5'-GGACAUAACAAG GAAA GAUTTAUCUUUCCUUGUUAUGUCC TT-3'(siRNA-1) and 5'-CCAUGGGAUAA AGAUGC UUTTAAGCAUCUUUAUCCCAUGGTT-3' (siRNA2). The negative control siRNA sequence was $5^{\prime}$-UUC UCCGAACGUGUCACGUTT-3. These siRNAs were transfected into BLCs with the aid of lipofectamine ${ }^{\circledR}$ RNAiMAX reagent (Invitrogen, Carlsbad, CA) according to the manufacturer's protocol. Following confirmation of the siRNA effect by western-blotting assay, activated siRNA-transfected BLCs were subjected to $\beta$-hexosaminidase assays following experimentally indicated pretreatments.

\section{Western blot}

We used western blots to investigate the effects of palbociclib on the activation of the FceRI signaling regulatory proteins Lyn and the MAPK signaling proteins $\mathrm{p} 38$, JNK, and ERK1/2, which have bene reported to be involved in mast cell activation [26]. BLCs were sensitized with $50 \mathrm{ng} / \mathrm{ml}$ DNP-IgE overnight and washed twice with PBS and placed in fresh media. After incubating with or without palbociclib at $37^{\circ} \mathrm{C}$ for $1 \mathrm{~h}$, BLCs were stimulated with $100 \mathrm{ng} / \mathrm{ml}$ DNP-HSA and then washed twice with PBS. Cells were lysed in RIPA buffer (Beyotime, Beijing, China) with a protease-inhibitor cocktail (Med Chem Express, Monmouth Junction, NJ). Cell lysates were centrifuged at 12,000 rpm for $15 \mathrm{~min}$. Supernatants were mixed with a loading sample buffer (Thermo Fisher Scientific) and denatured by heating for $10 \mathrm{~min}$ at $100{ }^{\circ} \mathrm{C}$. Proteins were separated by sodium dodecyl sulfate-polyacrylamide gel electrophoresis and transferred to polyvinylidene difluoride membranes (Merck 
Millipore, Billerica MA). After incubating with a primary antibody in tris-buffered saline with $0.1 \%$ tween 20 buffer that contained $5 \%$ bovine serum albumin or skim milk. The membranes were incubated with horse-radish peroxidase-conjugated secondary antibodies for $1 \mathrm{~h}$ at room temperature in the same buffer. Chemiluminescence reagents (Meilun, Dalian, China) were applied according to the manufacturer's protocol.

\section{PCA model}

PCA mice were used to examine the effects of palbociclib on IgE-mediated allergic reaction in vivo. The PCA model is an acute allergic animal model wherein allergic reactions are induced by antigen stimulation of mast cells in ear skin $[19,20]$. Briefly, BALB/c mice (female, 4-5 weeks-old, 5 per group) were injected intradermally with $0.5 \mu \mathrm{g}$ of DNP-IgE in the left ear. After a 24-h infiltration period, palbociclib (25 mg/kg or $50 \mathrm{mg} / \mathrm{kg}$ ) or ketotifen (100 mg/kg, positive control) dissolved in physiological saline was injected intraperitoneally [19-21]. One hour later, $200 \mu \mathrm{l}$ of $5 \mathrm{mg} / \mathrm{ml}$ Evans blue solution containing $0.1 \mathrm{mg} / \mathrm{ml}$ DNP-HSA was administered into the tail vein. The mice were euthanized by cervical dislocation an hour after Evans blue injection. The dye was extracted from dissected ears in $700 \mu \mathrm{l}$ of formamide for $12 \mathrm{~h}$ at $62{ }^{\circ} \mathrm{C}$ and quantitated by a spectrophotometer at $620 \mathrm{~nm}$. Ear thickness was measured with a dial thickness gauge.

\section{ASA model}

The ASA model has been used to examine immediate-type hypersensitivity, which has been shown to be strongly associated with mast cells [21]. BALB/c mice (female, 4-5 weeks-old, 5 per group) were sensitized with OVA (100 $\mu$ g OVA and $2 \mathrm{mg}$ alum adjuvant in 200 $\mu \mathrm{PBS})$, by intraperitoneal injection on day 0 and day 7 as described previously [21]. Subsequently, palbociclib (50 $\mathrm{mg} / \mathrm{kg}$ ) and ketotifen $(50 \mathrm{mg} / \mathrm{kg}$ ) injections were given intraperitoneally on days 9,11 , and 13 . The animals were challenged with OVA injections following sensitization. On day 14, $200 \mu \mathrm{g}$ of OVA was injected intraperitoneally, and rectal temperature was measured every $10 \mathrm{~min}$ for $90 \mathrm{~min}$. After $90 \mathrm{~min}$, a blood sample was obtained from the tail of each mouse. Blood IL-4 and IL-10 levels were measured by ELISA (Shanghai Huzhen Biotechnology Co., Ltd. Shanghai, China) according to the manufacturer's protocol.

\section{Statistical analysis}

The data are presented as the means with standard deviations (SDs) of at least three independent experiments for cell experiments and of 5 mice per group for animal experiments. Statistical analyses were performed in
Prism 7.0 (GraphPad Software, Inc.). One-way analyses of variance (ANOVAs) and Dunnett's post-hoc tests for multiple comparisons were applied to detect inter-group differences with a significance criterion of $p<0.05$.

\section{Results \\ Palbociclib inhibited mast cell degranulation without cytotoxicity}

Cell viability assays revealed no evidence of palbociclib cytotoxicity in BLCs or BMMCs (Fig. 1a) following $24 \mathrm{~h}$ of exposure at concentrations $<100 \mu \mathrm{M}$. Palbociclib treatment reduced levels of released granule-related mediators (histamine and $\beta$-hexosaminidase) dose dependently in DNP-HSA activated BLCs (Fig. 1b, c). Similar degranulation inhibition was seen in BMMCs treated with palbociclib (Fig. 1e). Cytometric analysis of palbociclib-treated BLCs showed dose-dependent inhibition of the upregulation of the expression of the mast cell activation marker CD63 (Fig. 1d).

\section{Palbociclib inhibited activation-associated morphological changes in mast cells}

Non-activated BLCs had an elongated shape with purple intra-cellular particles, whereas activated BLCs had irregular shapes and released purple particles extracellularly. Palbociclib inhibited activation-associated morphological changes and degranulation (particle release) in activated BLCs significantly (Fig. 2a). Non-activated BLCs had a spindle shape and uniformly distributed F-actin. Activated BLCs became elliptical in accordance with their F-actin cytoskeletal changes. Pretreatment with palbociclib inhibited activation-associated shape changes and F-actin cytoskeleton decomposition in activated BLCs (Fig. 2b).

\section{Palbociclib inhibited signaling pathways involved in mast cell activation}

Palbociclib pretreatment, prior to a DNP-HSA challenge, inhibited activation of Lyn as well as activation of MAPKs (p38, JNK, and ERK) in BLCs, as evidenced by decreased levels of p-Lyn, p-p38, p-JNK, and p-ERK1/2 (Fig. 3a, b). The effects of palbociclib on Lyn and MAPK signaling molecules exhibited dose dependence. Experiments with small molecule inhibitors or siRNAs intended to investigate whether palbociclib suppression of mast cell degradation involves down-regulation of Lyn and MAPK signaling showed no statistically significant differences in $\beta$-hexosaminidase release levels in DNP-HSA activated BLCs between cells treated with palbociclib alone and cells treated with palbociclib plus the Lyn signaling inhibitor bafetinib (Fig. 3c). Lyn expression was reduced in siRNA-treated BLCs (Fig. 3d). Similarly, down-regulation of Lyn expression in BLCs did not affect palbociclib 

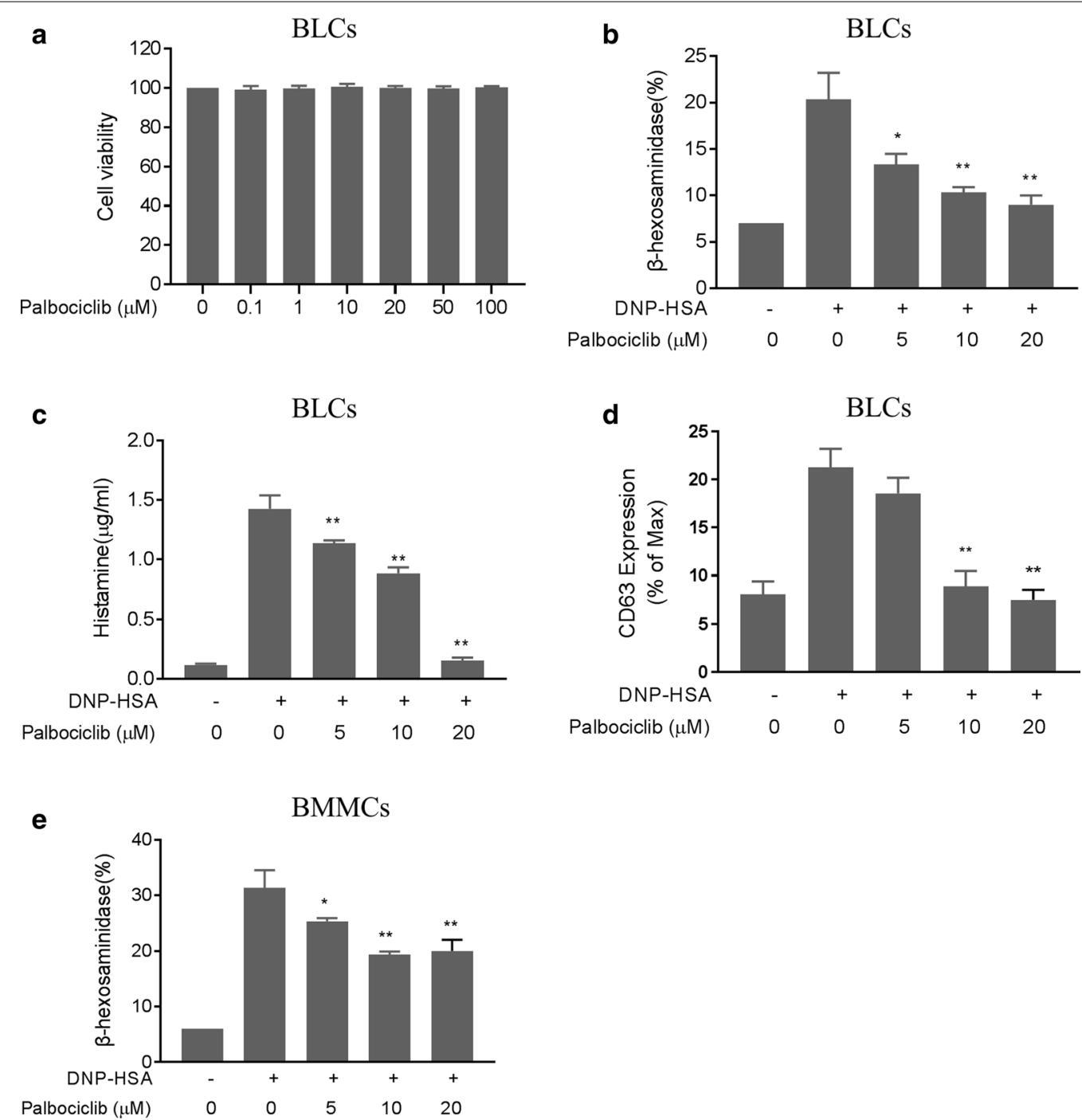

Fig. 1 Palbociclib attenuation of mast cell degranulation. a Cell viability of B LCs following DNP-HSA challenge with or without 1-h palbociclib pretreatment (BLCs had been anti-DNP IgE-sensitized and incubated with palbociclib for $24 \mathrm{~h}$ prior to the challenge). $\mathbf{b} \beta$-Hexosaminidase release from BLCs in a. c Histamine release from BLCs in A. $\mathbf{d}$ Flow cytometric analysis of CD63 expression in BLCs. e $\beta$-Hexosaminidase release from BMMCs stimulated with $100 \mathrm{ng} / \mathrm{ml}$ DNP-HSA for $30 \mathrm{~min}$ (prior $50 \mathrm{ng} / \mathrm{ml}$ DNP-specific lgE priming with or without 1-h palbociclib pretreatment). Means \pm SDs of 3 independent experiments are shown; ${ }^{*} p<0.05,{ }^{* *} p<0.01$ vs. the HSA-DNP group

inhibition of mast cell activation, as evidenced by detection of $\beta$-hexosaminidase release (Fig. 3e). Similar results were obtained with the ERK inhibitor U0126, the JNK inhibitor SP600125, and the p38 inhibitor SB203580 (Fig. 3f). These results suggest that palbociclib inhibition of mast cell activation may involve suppression of Lyn and MAPK signaling.

\section{Palbociclib attenuated PCA in vivo}

Inhibition of mast cell activation was confirmed in a positive control group treated with the mast cell stabilizer ketotifen. When ears were injected with $4 \%$ Evans blue dye mixed with antigen in PCA tests, they showed marked thickening in response and Evans blue solution poured out from PCA reaction sites, demonstrating vascular hyperpermeability. Dye solution extravasation and ear thickening were inhibited by $25 \mathrm{mg} / \mathrm{kg}$ or $50 \mathrm{mg} / \mathrm{kg}$ palbociclib (Fig. 4).

\section{Palbociclib attenuated ASA in vivo}

Mice were sensitized by repeated administration of OVA with alum adjuvant, and anaphylaxis was induced with an intraperitoneal OVA challenge, as shown in Fig. $5 \mathrm{a}$. Ketotifen treatment was as positive control. OVA mice 


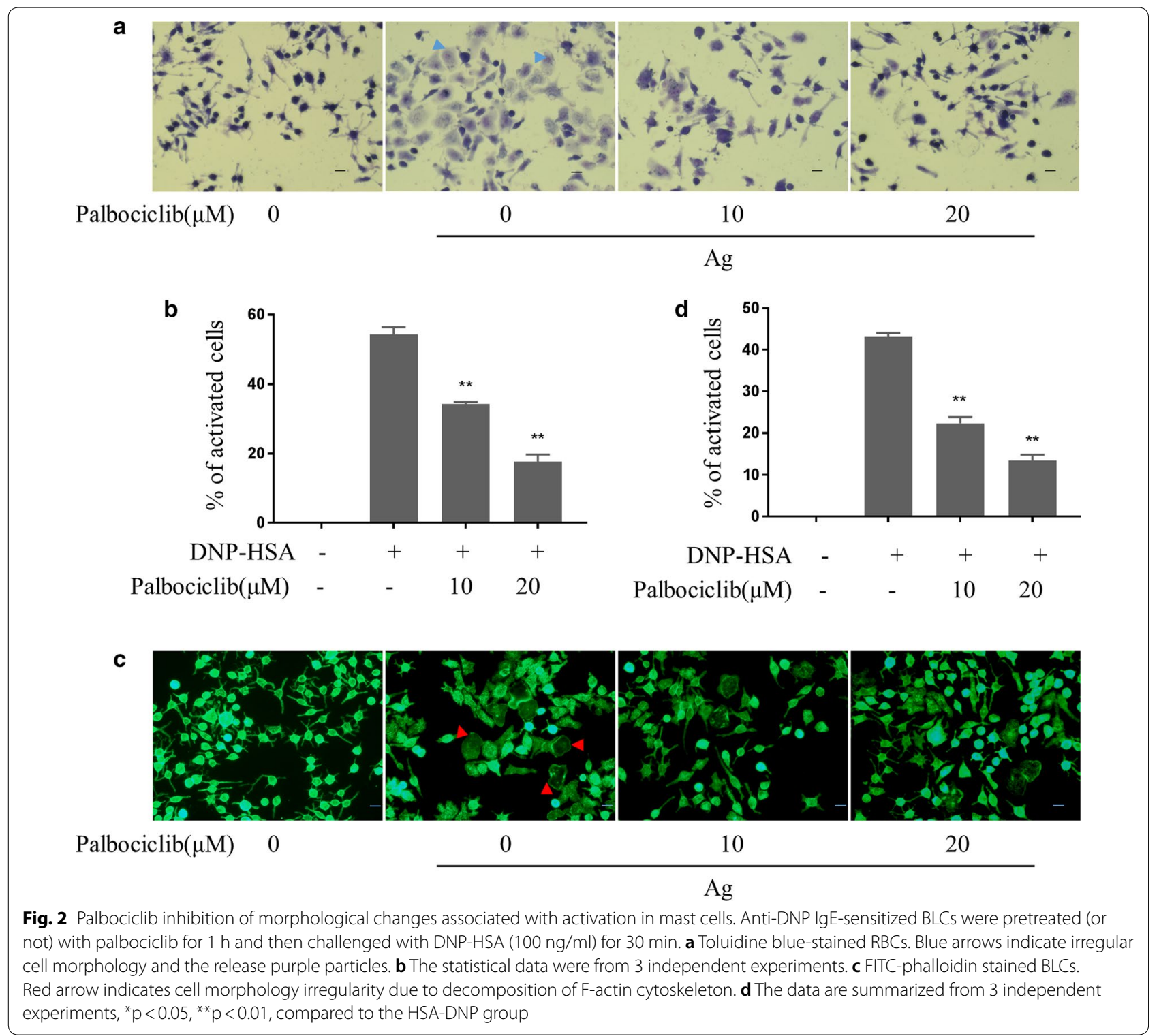

exhibited decreasing rectal temperatures 30-50 min after the OVA challenge injection, and these temperature reductions were attenuated by palbociclib (Fig. 5b). Concomitantly, total serum IL-4 and IL-10 levels reflective of inflammation were increased after the OVA challenge and those increases were suppressed by palbociclib (Fig. 5c, d).

\section{Discussion}

In the present study, palbociclib exhibited inhibitory effects on mast cell degranulation, as evidenced by reduced release of histamine and $\beta$-hexosaminidase by DNP-IgE/HAS-stimulated BLCs and BMMCs. In our in vivo experiments, palbociclib attenuated the DNP-IgE/
HSA-induced PCA reaction (Evans blue extravasation) dose-dependently and suppressed ASA responses (i.e. OVA challenge-induced body temperature reduction and serum IL-4 or IL-10 level increases). Together, these results show that the CDK4/6 inhibitor palbociclib can suppress IgE-mediated mast cell activation in vitro and in vivo.

During mast cell degranulation, morphological changes occur due to the actions of contractile microfilaments [29]. Mast cell activation via aggregation of IgE-Fc\&RI complexes causes degranulation and release of proinflammatory mediators, and these processes involve F-actin reorganization [25, 29]. Our findings showing that pretreatment with palbociclib inhibited cell shape 


\section{a}

p-LYN

LYN

GAPDH

DNP-HSA

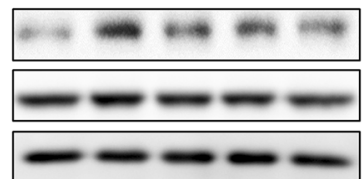

Palbociclib $(\mu \mathrm{M}) \quad 0 \quad 0 \quad 10 \quad 20 \quad 40$

C
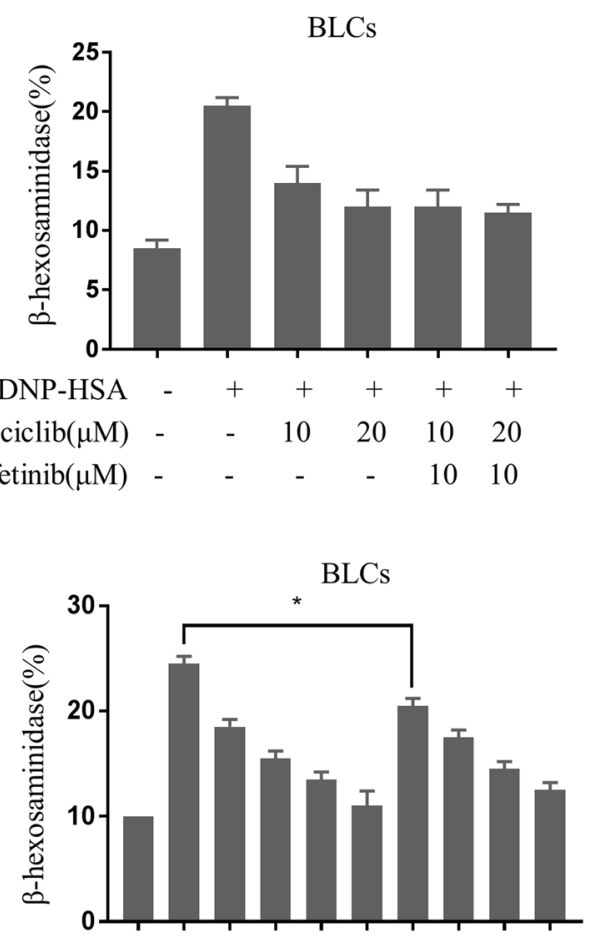

Negative control $+++++\ldots$ SiRNA 1 - - $-c_{-}+++$

DNP-HSA - ++++++++

Palbociclib $(\mu \mathrm{M})$ - $\quad-51020$ - 5 - 51020

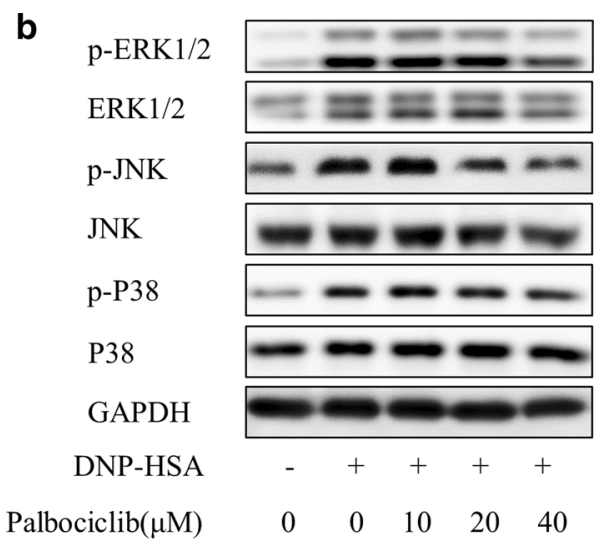

d

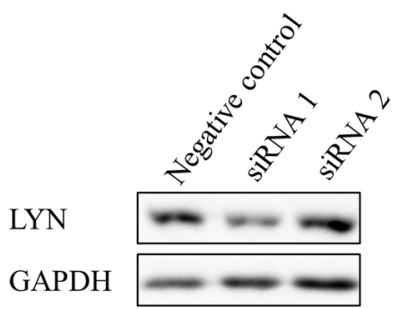

f

BLCs

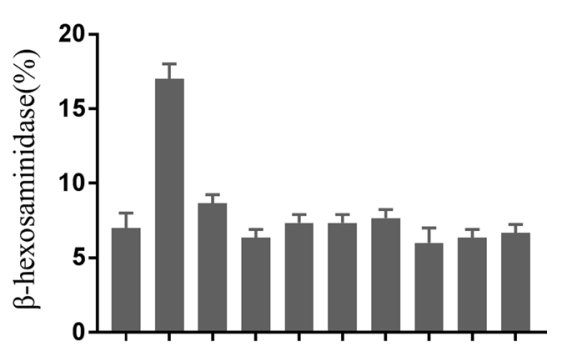

DNP-HSA - + + + + + + +

Palbociclib( $\mu \mathrm{M})$ - - 1010101020202020

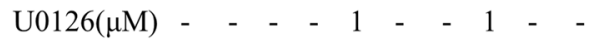

$\mathrm{SP} 600125(\mu \mathrm{M})$ - $\quad-\quad-\quad-10-\quad-10$ -

$\mathrm{SB} 203580(\mu \mathrm{M})$ - $\quad-\quad-\quad-10-\quad-10$

Fig. 3 Palbociclib-mediated reduction in levels of phosphorylated proteins that are involved in mast cell activation. Western blots of total lysate samples from activated mast cells (see "Materials and methods") demonstrating palbociclib treatment ( $0 \mu \mathrm{M}, 10 \mu \mathrm{M}, 20 \mu \mathrm{M}$, and $40 \mu \mathrm{M})$ inhibition of Lyn activation (a) and MAPK (p38, JNK, and ERK1/2) activation (b). c $\beta$-Hexosaminidase release from activated BLCs subjected to 1-h pretreatments (as experimentally indicated) prior to the challenge. $\mathbf{d}$ Western blot analysis of Lyn expression in RBL-2H3 cells transfected with siRNA-Lyn. e $\beta$-Hexosaminidase release from activated BLCs pretreated with siRNA-Lyn and palbociclib. $\mathbf{f} \beta$-Hexosaminidase release from activated BLCs pretreated with signaling inhibitors (ERK inhibitor U0126, JNK inhibitor SP600125, and p38 inhibitor SB203580) for $1 \mathrm{~h}$ prior to the challenge

changes and cytoskeletal decomposition in BLCs resemble previously reported inhibitory effects of coptisine on mast cell degranulation [24].
Activation of protein tyrosine kinases is the earliest detectable signaling response to FceRI cross-linking on mast cells [26]. Upon tyrosine kinase activation, 
a

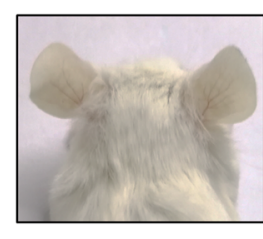

Ctrl

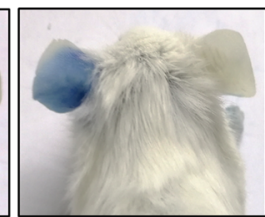

0

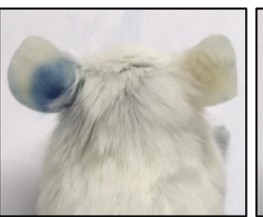

25

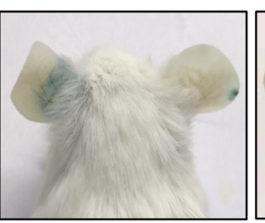

50

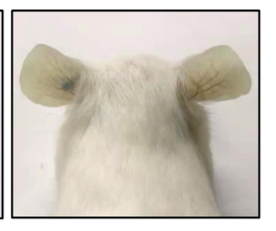

50

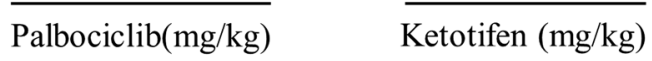

$\mathrm{Ag}$

b
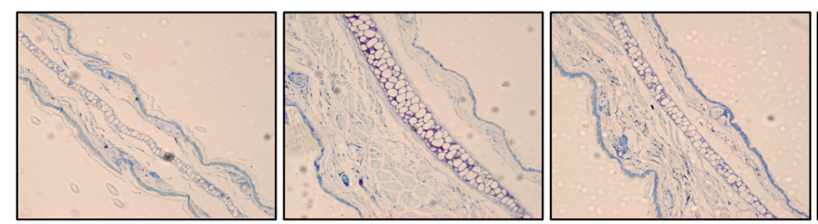

0

25

Palbociclib $(\mathrm{mg} / \mathrm{kg})$

Ketotifen $(\mathrm{mg} / \mathrm{kg})$

$\mathrm{Ag}$

c

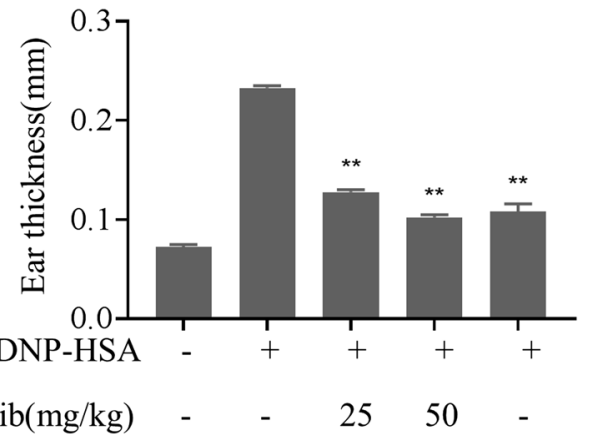

$\begin{array}{llllll}\text { Palbociclib }(\mathrm{mg} / \mathrm{kg}) & - & - & 25 & 50 & - \\ \text { Ketotifen }(\mathrm{mg} / \mathrm{kg}) & - & - & - & - & 50\end{array}$ d

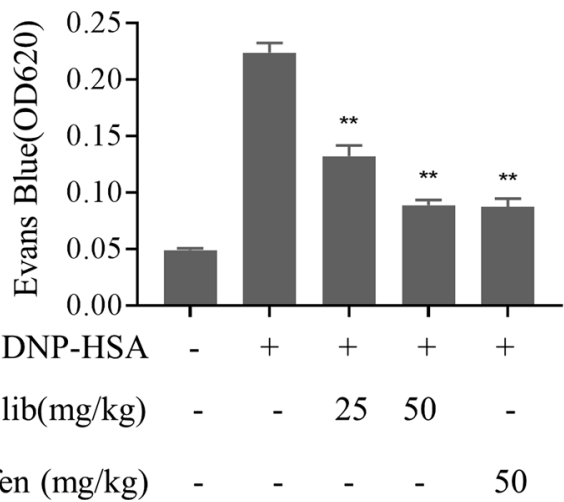

Fig. 4 Palbociclib suppression of PCA in vivo. Mouse ear skin ( $N=5 /$ group) was sensitized with anti-DNP IgE, treated (or not) with palbociclib, and injected with $20 \mu \mathrm{g}$ DNP-HSA containing 1\% Evans blue as described in detail in "Materials and methods". Ketotifen treatment was as positive control. a Representative images of PCA mouse ears. $\mathbf{b}$ Representative photomicrographs of PCA ear tissue sections. Palbociclib reverses PCA-induced ear thickening (c) and PCA-induced increases in Evans Blue $\mathrm{OD}_{620 \mathrm{~nm}}$. Means \pm SDs of 3 independent experiments are shown; ${ }^{*} p<0.05$, ${ }^{* *} p<0.01$ vs. control

molecular mechanisms involving the Src family kinase Lyn [30] and/or intracellular signaling via MAPKs [26, 31] promotes mast cell degranulation. Mast cell activation inhibitors, including the corticosteroid dexamethasone [21], have been shown to suppress mast cell activation by down-regulating signaling pathways. Here, similarly, we observed that palbociclib suppressed Lyn activation and MAPK pathway signaling.

Drug repurposing, wherein previously developed pharmacotherapies are used in new applications, can accelerate clinical drug discovery and development [32]. The major advantages of drug repurposing are previously established low cytotoxicity and pharmacokinetic activity [33]. For example, metformin, a widely used anti-diabetic drug [34] that also has anti-cancer effects [35-37], has been shown to inhibit IgE and aryl hydrocarbon receptor-mediated mast cell activation in vitro and in vivo [38]. Additionally, the antidiarrheal medicine berberine, which is widely used for gastrointestinal ailments such as bacterial gastroenteritis and dysentery [39], has been found to suppress mast cell-mediated allergic responses via down-regulation of FceRI activation and MAPK signaling [40]. Hence, searching among existing drugs for pharmacotherapies that can be repurposed into novel allergic 


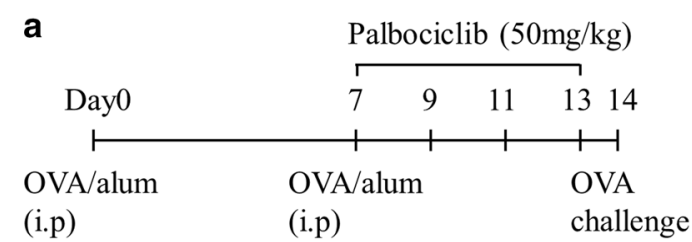

C

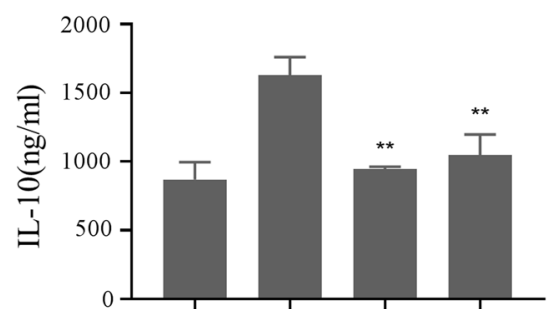

Palbociclib $(\mathrm{mg} / \mathrm{kg}) \quad-\quad-\quad 50 \quad-$

Ketotifen $(\mathrm{mg} / \mathrm{kg}) \quad-\quad-\quad-\quad-50$

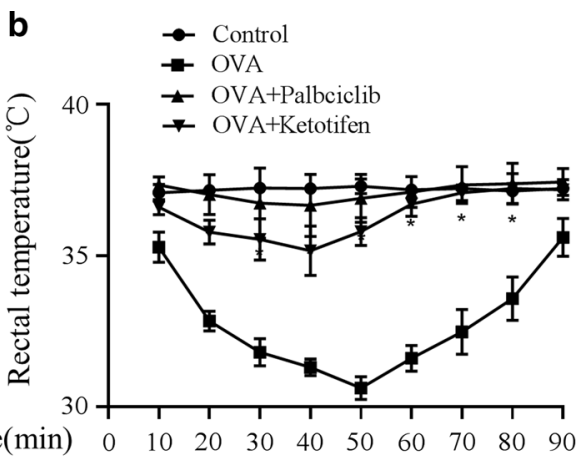

d

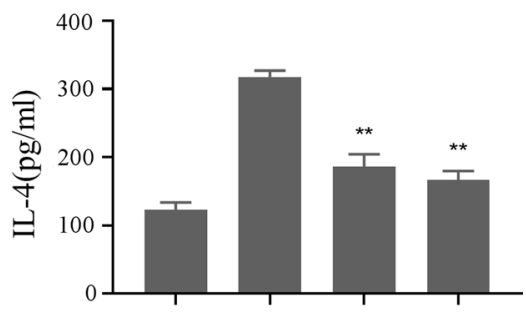

Palbociclib $(\mathrm{mg} / \mathrm{kg}) \quad-\quad-\quad 50 \quad-$

Ketotifen $(\mathrm{mg} / \mathrm{kg}) \quad-\quad-\quad-\quad-50$

Fig. 5 Palbociclib suppression of ASA in vivo. a ASA model protocol ( $N=5 / g r o u p)$. Ketotifen treatment was as positive control. Palbociclib prevents ASA-induced reductions in body temperature $\mathbf{b}$ as well as ASA-induced increases in IL-10 (c) and IL-4 (d) serum levels in ASA mice (determined by ELISA). Means $\pm S D$ s of 3 independent experiments are shown; ${ }^{*} p<0.05,{ }^{* *} p<0.01 \mathrm{vs}$. control

disease treatments that target mast cell activation represents a promising strategy.

Currently, palbociclib is being used as an anti-cancer drug. It inhibits the growth of cancer cells by inhibiting CDK4/6. In 2017, it was approved by the US FDA as an adjuvant therapy, with endocrine blockers, for ER+/ HER2 - advanced breast cancer in postmenopausal women. Pooled safety analysis (PALOMA trial) revealed a peak incidence of adverse events in the first 6 months of treatment, with a subsequent decrease in incidence over time [41]. In clinical use, oral palbociclib is generally well-tolerated at its oncological dosage of $125 \mathrm{mg}$ daily on a 21-day on, 7-day off schedule $[42,43]$. When administered at a dose of $150 \mathrm{mg} / \mathrm{kg}$, palbociclib does not affect body weight in mice [44]. Palbociclib's low toxicity profile and ability to inhibit mast cell activation in our murine models suggest that palbociclib could be used to alleviate IgE-mediated allergic diseases in human patients.

Palbociclib inhibition of cell growth by way of cell cycle arrest $[45,46]$, suggests that mast cell activation may require unimpeded cell cycle progression. Upregulation of CDK6 expression can enhance MAPK and NF- $\mathrm{kB}$ signaling $[47,48]$, both of which have been associated with mast cell activation [26]. Previous demonstrations showing that palbociclib can inhibit neoplastic mast cell proliferation [49] did not indicate whether palbociclib also inhibits mast cell activation, and specifically cell degradation, a key allergic disease treatment target. Hence, given palbociclib's CDK inhibitory actions and its ability to suppress signaling molecule expression and/ or activation, we hypothesize that palbociclib administered at a low-cytotoxicity dose may exert anti-IgEmediated allergy effects by down-regulating of MAPK and/or NF- $\mathrm{kB}$ signaling downstream of CDK6 inhibition via FceRI, whose activation may be modulated by the Src family kinase Lyn [30]. Lyn, interacting with FceRI $\beta$, is indispensable for FceRI-mediated human mast cell activation, and specific inhibition of Lyn signaling may represent a new therapeutic strategy for the treatment of human allergic diseases [50]. Our results showed that palbociclib inhibition of mast cell activation may involve suppression of Lyn and/or MAPK signaling.

Interestingly, palbociclib reduced the total serum IL-10 levels in the ASA model. IL-10 is secreted by a wide variety of cell types, even including mast cells [51]. IL-10 enhances IgE-mediated mast cell responses and is necessary mediator of allergy development in vivo [51]. Additionally, IL-10 has been shown to be critical for 
Th2 responses in a murine allergy model [52]. The present results suggest that palbociclib inhibition of mast cells may reduce IL-10 levels, or even Th2 cells. These possibilities need to be examined directly with further experimentation.

In conclusion, our findings showing that the CDK4/6 inhibitor palbociclib can suppress IgE-mediated mast cell activation in vitro and in vivo suggest that palbociclib is a potential therapeutic candidate for treating mast cell-mediated allergic diseases, including allergic rhinitis, atopic dermatitis, and anaphylaxis [27, 28]. Inhibition of mast cell activation-an important pathogenic process in IgE-induced allergic reactions [11]-represents a novel strategy for relieving allergic symptoms and treating allergic reactions.

\section{Acknowledgements}

We thank the other members of Ji Kunmei lab for their critical comments.

\section{Authors' contributions \\ Conceived and designed the study: JKM and CJ. Analyzed the data: CJJ and CJJ. Performed the studies: CJJ, HYB and ZLN. Contributed reagents/materi- als/analysis tools: CJJ and JKM. Wrote the manuscript: HYB, CJJ and JKM. All authors read and approved the final manuscript.}

\section{Funding}

The present study was supported in part by research funding from the National Natural Science Foundation of China (Grant Nos. 81571570 and 81602595), Guangdong Province (Grant Nos. 2016A030313039 and 2017A010105014), and Shenzhen City 2016 Biochemistry Discipline Construction, the Natural Science Foundation of Shenzhen City (JCYJ20170818142053544).

\section{Availability of data and materials}

The datasets used and/or analyzed during the current study are available from the corresponding author on reasonable request.

\section{Ethics approval and consent to participate}

All studies involving mice were performed according to protocols approved by the Animal Care and Use Committee of the School of Medicine of Shenzhen University.

\section{Consent for publication}

Not applicable.

\section{Competing interests}

The authors declare that they have no competing interests.

Received: 5 June 2019 Accepted: 14 August 2019

Published online: 20 August 2019

\section{References}

1. Galli SJ, Tsai M. IgE and mast cells in allergic disease. Nat Med. 2012;18(5):693-704.

2. Simons FE, Ebisawa M, Sanchez-Borges M, Thong BY, Worm M, Tanno LK, et al. 2015 update of the evidence base: World Allergy Organization anaphylaxis guidelines. World Allergy Organ J. 2015;8(1):32.

3. Flohr C, Quinnell RJ, Britton J. Do helminth parasites protect against atopy and allergic disease? Clin Exp Allergy. 2009;39(1):20-32.

4. Kim JD, Kim DK, Kim HS, Kim AR, Kim B, Her E, et al. Morus bombycis extract suppresses mast cell activation and IgE-mediated allergic reaction in mice. J Ethnopharmacol. 2013;146(1):287-93.
5. Gilfillan AM, Beaven MA. Regulation of mast cell responses in health and disease. Crit Rev Immunol. 2011;31(6):475-529.

6. Hu J, Chen J, Ye L, Cai Z, Sun J, Ji K. Anti-lgE therapy for IgE-mediated allergic diseases: from neutralizing $\lg E$ antibodies to eliminating $\lg \mathrm{E}(+) \mathrm{B}$ cells. Clin Transl Allergy. 2018;8:27.

7. Beaven MA. Our perception of the mast cell from Paul Ehrlich to now. Eur J Immunol. 2009;39(1):11-25.

8. White MV. The role of histamine in allergic diseases. J Allergy Clin Immunol. 1990;86(4 Pt 2):599-605.

9. Meiler F, Klunker S, Zimmermann M, Akdis CA, Akdis M. Distinct regulation of $\operatorname{lgE}, \operatorname{lgG} 4$ and $\lg A$ by $T$ regulatory cells and toll-like receptors. Allergy. 2008;63(11):1455-63.

10. Kaliner MA. Azelastine and olopatadine in the treatment of allergic rhinitis. Ann Allergy Asthma Immunol. 2009;103(5):373-80.

11. Anvari S, Miller J, Yeh CY, Davis CM. IgE-mediated food allergy. Clin Rev Allergy Immunol. 2018. https://doi.org/10.1007/s12016-018-8710-3.

12. Van Hoecke $H$, Vandenbulcke L, Van Cauwenberge P. Histamine and leukotriene receptor antagonism in the treatment of allergic rhinitis: an update. Drugs. 2007;67(18):2717-26.

13. Zhang T, Finn DF, Barlow JW, Walsh JJ. Mast cell stabilisers. Eur J Pharmacol. 2016;778:158-68.

14. Alachkar A, Khan N, Lazewska D, Kiec-Kononowicz K, Sadek B. Histamine $\mathrm{H} 3$ receptor antagonist $\mathrm{E} 177$ attenuates amnesia induced by dizocilpine without modulation of anxiety-like behaviors in rats. Neuropsychiatr Dis Treat. 2019;15:531-42.

15. Tanno LK, Alvarez-Perea A, Pouessel G. Therapeutic approach of anaphylaxis. Curr Opin Allergy Clin Immunol. 2019;19(3):198-203.

16. Finn RS, Martin M, Rugo HS, Jones S, Im SA, Gelmon K, et al. Palbociclib and letrozole in advanced breast cancer. N Engl J Med. 2016;375(20):1925-36.

17. Clark AS, Karasic TB, DeMichele A, Vaughn DJ, O'Hara M, Perini R, et al. Palbociclib (PD0332991)-a selective and potent cyclin-dependent kinase inhibitor: a review of pharmacodynamics and clinical development. JAMA Oncol. 2016;2(2):253-60.

18. Caslin HL, Taruselli MT, Paranjape A, Kiwanuka K, Haque T, Chumanevich AP, et al. The use of human and mouse mast cell and basophil cultures to assess type 2 inflammation. Methods Mol Biol. 2018;1799:81-92.

19. Shao C, Fu B, Ji N, Pan S, Zhao X, Zhang Z, et al. Alisol B 23-acetate inhibits $\mathrm{lgE} / \mathrm{Ag}$-mediated mast cell activation and allergic reaction. Int J Mol Sci. 2018;19:12.

20. Park YH, Kim DK, Kim HW, Kim HS, Lee D, Lee MB, et al. Repositioning of anti-cancer drug candidate, AZD7762, to an anti-allergic drug suppressing IgE-mediated mast cells and allergic responses via the inhibition of Lyn and Fyn. Biochem Pharmacol. 2018;154:270-7.

21. Kim MJ, Kim YY, Choi YA, Baek MC, Lee B, Park PH, et al. Elaeocarpusin inhibits mast cell-mediated allergic inflammation. Front Pharmacol. 2018:9:591.

22. Groot KormelinkT, Arkesteijn GJ, van de Lest CH, Geerts WJ, Goerdayal SS, Altelaar MA, et al. Mast cell degranulation is accompanied by the release of a selective subset of extracellular vesicles that contain mast cell-specific proteases. J Immunol. 2016;197(8):3382-92.

23. Puebla-Osorio N, Sarchio SNE, Ullrich SE, Byrne SN. Detection of infiltrating mast cells using a modified toluidine blue staining. Methods Mol Biol. 2017;1627:213-22.

24. Fu S, Ni S, Wang D, Hong T. Coptisine suppresses mast cell degranulation and ovalbumin-induced allergic rhinitis. Molecules. 2018;23(11):3039.

25. Ang WX, Church AM, Kulis M, Choi HW, Burks AW, Abraham SN. Mast cell desensitization inhibits calcium flux and aberrantly remodels actin. J Clin Invest. 2016;126(11):4103-18.

26. Gilfillan AM, Tkaczyk C. Integrated signalling pathways for mast-cell activation. Nat Rev Immunol. 2006;6(3):218-30.

27. Begin P, Nadeau KC. Epigenetic regulation of asthma and allergic disease. Allergy Asthma Clin Immunol. 2014;10(1):27.

28. Bischoff SC. Role of mast cells in allergic and non-allergic immune responses: comparison of human and murine data. Nat Rev Immunol. 2007;7(2):93-104.

29. Joseph LB, Composto GM, Perez RM, Kim HD, Casillas RP, Heindel ND, et al. Sulfur mustard induced mast cell degranulation in mouse skin is inhibited by a novel anti-inflammatory and anticholinergic bifunctional prodrug. Toxicol Lett. 2018;293:77-81. 
30. VoTS, Kim YS, Ngo DH, Le PU, Kim SY, Kim SK. Spirulina maxima peptides suppress mast cell degranulation via inactivating Akt and MAPKs phosphorylation in RBL-2H3 cells. Int J Biol Macromol. 2018;118(Pt B):2224-9.

31. Mkaddem SB, Murua A, Flament H, Titeca-Beauport D, Bounaix C, Danelli $L$, et al. Lyn and Fyn function as molecular switches that control immunoreceptors to direct homeostasis or inflammation. Nat Commun. 2017;8(1):246

32. Wilkinson GF, Pritchard K. In vitro screening for drug repositioning. J Biomol Screen. 2015;20(2):167-79.

33. Novac N. Challenges and opportunities of drug repositioning. Trends Pharmacol Sci. 2013;34(5):267-72.

34. Hostalek U, Gwilt M, Hildemann S. Therapeutic use of metformin in prediabetes and diabetes prevention. Drugs. 2015;75(10):1071-94.

35. Farajzadeh R, Pilehvar-Soltanahmadi Y, Dadashpour M, Javidfar S, LotfiAttari J, Sadeghzadeh $\mathrm{H}$, et al. Nano-encapsulated metformin-curcumin in PLGA/PEG inhibits synergistically growth and hTERT gene expression in human breast cancer cells. Artif Cells Nanomed Biotechnol. 2018;46(5):917-25.

36. Faramarzi L, Dadashpour M, Sadeghzadeh H, Mahdavi M, Zarghami N. Enhanced anti-proliferative and pro-apoptotic effects of metformin encapsulated PLGA-PEG nanoparticles on SKOV3 human ovarian carcinoma cells. Artif Cells Nanomed Biotechnol. 2019;47(1):737-46.

37. Coyle C, Cafferty FH, Vale C, Langley RE. Metformin as an adjuvant treatment for cancer: a systematic review and meta-analysis. Ann Oncol. 2016;27(12):2184-95

38. Wang HC, Huang SK. Metformin inhibits IgE- and aryl hydrocarbon receptor-mediated mast cell activation in vitro and in vivo. Eur J Immunol. 2018;48(12):1989-96.

39. Wang $H$, Zhu C, Ying Y, Luo L, Huang D, Luo Z. Metformin and berberine two versatile drugs in treatment of common metabolic diseases. Oncotarget. 2018;9(11):10135-46.

40. Fu S, Ni S, Wang D, Fu M, Hong T. Berberine suppresses mast cell-mediated allergic responses via regulating FcvarepsilonRI-mediated and MAPK signaling. Int Immunopharmacol. 2019;71:1-6.

41. Ettl J, Harbeck N. The safety and efficacy of palbociclib in the treatment of metastatic breast cancer. Expert Rev Anticancer Ther. 2017;17(8):661-8.

42. Finn RS, Crown JP, Lang I, Boer K, Bondarenko IM, Kulyk SO, et al. The cyclin-dependent kinase 4/6 inhibitor palbociclib in combination with letrozole versus letrozole alone as first-line treatment of oestrogen receptor-positive, HER2-negative, advanced breast cancer (PALOMA-1/ TRIO-18): a randomised phase 2 study. Lancet Oncol. 2015;16(1):25-35.
43. Thill M, Schmidt M. Management of adverse events during cyclindependent kinase 4/6 (CDK4/6) inhibitor-based treatment in breast cancer. Ther Adv Med Oncol. 2018;10:1758835918793326.

44. Fry DW, Harvey PJ, Keller PR, Elliott WL, Meade M, Trachet E, et al. Specific inhibition of cyclin-dependent kinase 4/6 by PD 0332991 and associated antitumor activity in human tumor xenografts. Mol Cancer Ther. 2004;3(11):1427-38.

45. Finn RS, Dering J, Conklin D, Kalous O, Cohen DJ, Desai AJ, et al. PD 0332991, a selective cyclin D kinase 4/6 inhibitor, preferentially inhibits proliferation of luminal estrogen receptor-positive human breast cancer cell lines in vitro. Breast Cancer Res. 2009;11(5):R77.

46. Goel S, DeCristo MJ, Watt AC, BrinJones H, Sceneay J, Li BB, et al. CDK4/6 inhibition triggers anti-tumour immunity. Nature. 2017;548(7668):471-5.

47. Handschick K, Beuerlein K, Jurida L, Bartkuhn M, Muller H, Soelch J, et al. Cyclin-dependent kinase 6 is a chromatin-bound cofactor for NF-kappaBdependent gene expression. Mol Cell. 2014;53(2):193-208.

48. Schmitz ML, Kracht M. Cyclin-dependent kinases as coregulators of inflammatory gene expression. Trends Pharmacol Sci. 2016;37(2):101-13.

49. Schneeweiss MA, Stefanzl G, Berger D, Eisenwort G, Jawhar M, Georg G, et al. The CDK4/6 inhibitor palbociclib exerts growth-inhibitory effects on neoplastic mast cells and synergizes with midostaurin in producing growth arrest. Blood. 2018;132(Suppl 1):1363.

50. Okayama Y, Kashiwakura Jl, Matsuda A, Sasaki-Sakamoto T, Nunomura S, Yokoi N, et al. The interaction between Lyn and FcepsilonRlbeta is indispensable for FcepsilonRI-mediated human mast cell activation. Allergy. 2012;67(10):1241-9.

51. Polukort SH, Rovatti J, Carlson L, Thompson C, Ser-Dolansky J, Kinney SR, et al. IL-10 enhances IgE-mediated mast cell responses and is essential for the development of experimental food allergy in IL-10-deficient mice. J Immunol. 2016;196(12):4865-76.

52. Laouini D, Alenius H, Bryce P, Oettgen H, Tsitsikov E, Geha RS. IL-10 is critical for Th2 responses in a murine model of allergic dermatitis. J Clin Invest. 2003;112(7):1058-66.

\section{Publisher's Note}

Springer Nature remains neutral with regard to jurisdictional claims in published maps and institutional affiliations.
Ready to submit your research? Choose BMC and benefit from:

- fast, convenient online submission

- thorough peer review by experienced researchers in your field

- rapid publication on acceptance

- support for research data, including large and complex data types

- gold Open Access which fosters wider collaboration and increased citations

- maximum visibility for your research: over 100M website views per year

At BMC, research is always in progress.

Learn more biomedcentral.com/submissions 